\title{
COSTA RICA: EL REFERÉNDUM, EL PODER POLÍTICO Y LA PARTICIPACIÓN CIUDADANA
}

El 7 de octubre de 2007, se realizó el primer referendo en la historia de Costa Rica. Se usó este instituto de democracia directa para dirimir la aprobación, o no, del Tratado de Libre Comercio con los Estados Unidos, Centroamérica y República Dominicana (TLC-EEUU-CA-RD). En el año anterior al llamado a referendo, el conflicto en torno al TLC se expresaba en terrenos paralelos, que no se encontraban. En el terreno de la politica institucionalizada, durante el 2006, la Comisión de Asuntos Internacionales tramitó el proyecto y lo remitió al Plenario Legislativo con un dictamen de mayoría afirmativo. Las fracciones opositoras elevaron a la Sala Cuarta una consulta de constitucionalidad sobre el proceso acelerado impuesto por el presidente de la Asamblea Legislativa, decisión que impidió la discusión de algunos capítulos medulares del Tratado. La oposición por su parte, se expresaba predominantemente en la movilización callejera que crecía en magnitud y diversidad, como se evidenció en las movilizaciones en todo el país el 23 y 24 de octubre de 2006 y en la marcha del 26 de febrero de 2007, la mayor en la historia del país hasta ese momento.

Conforme fue avanzando la polarización (politica y de espacios políticos) en torno al TLC y ante la ausencia de diálogo y negociación para buscar acuerdos politicos, distintos sectores se expresaron a favor del referendo para dirimir las diferencias. Desde hacía varios años se discutía en la esfera pública la posibilidad de introducir mecanismos de democracia directa para decidir temas que dividían a la sociedad y el referendo contaba con un apoyo muy mayoritario de la población. En un sondeo telefónico realizado en medio de las protestas contra la privatización de las telecomunicaciones en el 2000, el 84\% de la población manifestó estar de acuerdo con una consulta popular (Campos, Raventós, 2004: 42). A pesar de esto, en la práctica, las autoridades políticas habian mostrado renuencia a introducir la legislación correspondiente.

La Asamblea Legislativa aprobó una reforma constitucional que introducía el referendo y la iniciativa popular en el 2002 y se dio un año para promulgar la ley correspondiente. Sin embargo, pasaron cuatro años antes de aprobarla a fines de febrero del 2006 y sólo después de que la Sala Constitucional le ordenara hacerlo ${ }^{1}$. El Presidente de la República, por su parte, se había opuesto en muchas ocasiones al uso del referendo para el

1 El 11 de mayo del 2005 la Sala Constitucional falló favorablemente una acción de inconstitucionalidad por omisión a la Asamblea Legislativa, por no haber fallado la ley reguladora del referendo. Esta acción fue interpuesta por el Defensor de los Habitantes y el ciudadano Gabriel Bonilla el 2 de setiembre de 2004. En ella alegaban que el 28 de mayo del 2002 la Asamblea Legislativa había aprobado la reforma constitucional 
TLC. Cuando el Tribunal Supremo de Elecciones aceptó la solicitud de llamado a consulta - primero por parte de un grupo de ciudadanos y luego por el Presidente de la República - la ley todavía no había sido reglamentada y la Procuraduría de la República había expresado opinión contraria a la factibilidad de someter el TLC a referendo (por contener materias con implicaciones fiscales). Había mucha desconfianza entre los sectores opositores sobre la equidad que tendría el proceso. Esta desconfianza se fundamentaba en la creciente desproporción en el financiamiento de campañas electorales, de acceso a los medios de comunicación y a los cuestionamientos de fraude que había habido en las elecciones del 2006. Así, la institución del referendo fue reglamentada sobre la marcha, en el contexto de una convocatoria concreta a consulta en torno a un tema que habia llevado a una fuerte polarización política y su desarrollo no parece haber contribuido a disminuirla.

A un año del referendo sobre el TLC publicamos este número de la Revista de Ciencias Sociales, dedicado a recoger algunas contribuciones a su análisis desde las ciencias sociales. Los artículos incluidos se originan en ponencias provenientes de proyectos de investigación presentadas en el III Congreso Latinoamericano de Ciencias Políticas celebrado en la Universidad de Costa Rica entre el 6 y el 8 de agosto de 2008 y en las V Jornadas de Investigación del Instituto de Investigaciones Sociales de la Universidad de Costa Rica, realizadas en el mes de setiembre del mismo año.

Los autores provienen de distintas disciplinas de las ciencias sociales y todos estuvieron involucrados en el proceso del referendo. Alberto Cortés Ramos, politólogo, fue el coordinador de "No comunicación", el área de comunicación de la campaña del No y participó en el Frente de la UCR contra el TLC. Florisabel Rodríguez, también politóloga, Miguel Gómez Barrantes, estadístico, y Wendy Chacón, economista, estuvieron a cargo de sondeos de opinión pública para distintos clientes de Procesos, una institución privada de investigación, capacitación y asesoría. Sindy Mora es socióloga y Anthony García es estudiante de sociología. Sindy coordina y Anthony participa en un proyecto de seguimiento de las acciones colectivas del Instituto de Investigaciones Sociales. Ambos participaron en actividades de información en sus comunidades. Jeremy Rayner es candidato al doctorado de antropología en la City University de Nueva York. Participó en varios Comités Patrióticos a partir de agosto de 2007 como parte del trabajo de campo de su investigación de tesis. Ciska Raventós participó en el Frente de la UCR contra el TLC y en el Comité Patriótico de Sabanilla durante la campaña del referendo. Este posicionamiento de los

8182 en la que se instauraba el referendo como mecanismo de sufragio a través del cual el pueblo puede aprobar y derogar leyes y reformar parcialmente la constitución y la iniciativa popular para que los ciudadanos puedan presentar proyectos de ley a la Asamblea Legislativa, $y$ había aprobado también un transitorio en el que establecía un plazo de un año para dictar las leyes especiales requeridas para regular estas instituciones. En el momento de presentar la acción de inconstitucionalidad habían pasado 27 meses sin que la Asamblea hubiera dictado las leyes correspondientes. En el momento en que se dio el fallo de la Sala habían pasado 36 meses. La Sala le impuso a la Asamblea Legislativa un plazo de seis meses para dictar las leyes, plazo que no fue cumplido al aprobar las leyes en marzo de 2006, diez meses después. 
autores revela un rasgo de la coyuntura del referendo, que llevó a la toma de posición de la mayor parte de los ciudadanos, especialmente de los académicos y profesionales.

Los artículos buscan responder preguntas que son politica y académicamente pertinentes: ¿Cuál es el balance de esta primera consulta popular en términos de la legitimidad del proceso? ¿De la regulación de la competencia entre las partes (Cortés, Raventós)? ¿Del régimen democrático y de la ciudadanía (Raventós)? ¿Cuál fue la participación de los medios de comunicación colectiva (Cortés, García y Mora)? ¿Cómo evolucionó la opinión pública a lo largo de los tres meses de campaña (Rodríguez, Gómez y Chacón)? ¿Cuáles fueron los principales temas de conflicto para la ciudadanía (Rodríguez, Gómez y Chacón)? ¿Cuál es la naturaleza de las organizaciones de resistencia al neoliberalismo que surgieron (o se fortalecieron) en la coyuntura del referendo (Rayner)? ¿Cómo han evolucionado en el año que ha transcurrido desde el referendo (Rayner)?

Estos artículos fueron escritos en los meses posteriores al referendo, $y$ en ese sentido constituyen algunas de las primeras contribuciones académicas a la comprensión de esta experiencia de democracia directa y de los procesos que provocó, procesos que marcarán las formas que tomará la política costarricense de los próximos años. Al publicarlas esperamos contribuir a la reflexión y el debate sobre este importante evento en la vida politica nacional.

Además de los contenidos del tema especial, en la sección de inventario bibliográfico, Antonio Murga hace un inventario de las contribuciones al estudio de la cultura política durante los últimos veinticinco años.

El número cierra con tres artículos: Luis E. Cuenca analiza la competencia deliberativa de participantes del proceso de presupuesto participativo en Porto Alegre, Sebastián Cutrona detalla la permanencia de las premisas básicas de la geopolítica tradicional a partir de las relaciones de los Estados Unidos con Rusia y Roy Alfaro distingue el rol de los modelos mentales espaciales en la aprehensión literaria.

Ciudad Universitaria Rodrigo Facio setiembre del 2008

Dra. Ciska Raventós Coordinadora de este número 
